\title{
Efficacy and Safety of IL-2 injection for the treatment of childhood solid tumors or lymphoma with malignant pleural effusion, ascites and pericardial effusion
}

\author{
Yu-Tong Zhang \\ the First Hospital of Jilin University \\ Xiao-dan Zhong \\ the First Hospital of Jilin University \\ Yan-li Gao \\ the First Hospital of Jilin University \\ Jian Chang ( $\square$ changjian@jlu.edu.cn ) \\ the First Hospital of Jilin University
}

\section{Research Article}

Keywords: pleural effusion, ascites, pericardial effusion, interleukin-2, pediatric cancer

Posted Date: June 9th, 2021

DOl: https://doi.org/10.21203/rs.3.rs-582305/v1

License: (c) (1) This work is licensed under a Creative Commons Attribution 4.0 International License.

Read Full License 


\section{Abstract}

Background Currently, no available coherent management protocol exists for pediatric cancers associated with pleural effusion, ascites, and pericardial effusion. This study aimed to retrospectively present our experience in treating pediatric cancer patients with pleural effusion, ascites, and pericardial effusion using interleukin-2 (IL-2) and dexamethasone (DEX) intracavitary injections.

Methods Between January 1st, 2008 and December 31st, 2020, medical reports of patients diagnosed with solid tumors or lymphoma were checked to identify those with concurrent $>2 \mathrm{~cm}$ pleural effusion and/or ascites and/or pericardial effusion. Patients diagnosed with effusions and treated with IL-2 were identified as being in the effusion group. Meanwhile, patients with the same primary tumors and effusions but did not receive interleukin 2 injection were reviewed and classified as the control group.

Results Forty patients with solid tumors and Sixty-six patients with lymphoma were further diagnosed with pleural effusion, ascites, or pericardial effusion. A total of eighty-five patients received IL-2 injection while the remaining twenty-one did not. When lymphoma and solid tumor patients were combined, the Kaplan Meier analysis revealed a significant difference between the two groups, with $p<0.01$ for event free survival (EFS) and $p<0.01$ for overall survival (OS), both of which had $p<0.01$. Hazard ratio was found to be 0.344 for OS and 0.352 for EFS.

Conclusions This retrospective study illustrates that thoracic, intraperitoneal, or pericardial injection of DEX plus IL-2 can be an effective and safe treatment for pediatric cancers with pleural effusion, ascites, and pericardial effusion.

\section{Introduction}

Malignant pleural effusion, ascites, and pericardial effusion are common complications of most pediatric cancers, including $50 \%$ of patients with lymphomas and $50 \%$ with other tumors (like all kinds of sarcomas, neuroblastoma (NB), and hepatoblastoma (HB))[1-3]. Malignant pleural effusion and pericardial effusion can cause breathlessness and are sometimes life-threatening. Moreover, hemorrhagic pleural effusion or ascites from a ruptured tumor may increase metastasis risk. As shown in a report from Children's Oncology Group (COG) protocol AHOD0031, pleural effusion is an independent risk factor for the relapse of Hodgkin lymphoma[3]. However, no coherent management protocol is currently found for pleural effusion, ascites, and pericardial effusion. It seems that pleural effusion, ascites, and pericardial effusion can only be resolved with systemic chemotherapy, which can not only immediately relieve the discomfort of children but also increase metastasis risk. This study retrospectively presents our twelveyear's experience in treating pleural effusion, ascites, and pericardial effusion with interleukin-2 (IL-2) and dexamethasone (DEX) intracavitary injections among pediatric cancer patients.

\section{Methods}


This work was a single-center, retrospective cohort study. The ethics committee of our hospital approved our study protocols. Medical records from patients confirmed with solid tumors or lymphoma between January $1^{\text {st }}, 2008$ and December $31^{\text {st }}, 2020$, were reviewed to identify patients diagnosed with $>2 \mathrm{~cm}$ pleural effusion, and/or more than grade 1 ascites, and/or more than small pericardial effusion. For pleural effusion, small effusion (SE) is described as any effusion measuring $2-3 \mathrm{~cm}$ in size. Moderate effusion (ME) is any effusion $>3 \mathrm{~cm}$ in size that reached the mid-thoracic level on computer tomography (CT) image. Large effusion (LE) is any effusion that extends from the lung base to the apex and displaces heart and mediastinum toward the opposite side[3]. For ascites, grade 1 (G1) is mild ascites only detectable by ultrasound, grade 2 (G2) is moderate ascites evident by moderate symmetrical distension of abdomen, grade 3 (G3) is large or gross ascites with marked abdominal distension[4]. For pericardial effusion, total effusion (sum of the anterior and posterior) is categorized as small (S, 1 to 9 $\mathrm{mm})$, moderate (M, 10 to $19 \mathrm{~mm})$, or large (L, $20 \mathrm{~mm}$ or more) [5]

Patients diagnosed with effusions who received IL-2 injection were classified as effusion group. Meanwhile, patients with the same primary tumors with effusions who did not obtain IL-2 injection were reviewed and classified as a control group. To diagnose solid tumors or lymphoma, a fine needle biopsy or open biopsy was performed routinely.

The following patient data were extracted, including age, gender, tumor type, tumor stage, clinical manifestations of pleural effusion, ascites and pericardial effusion, therapeutic regimens of pleural effusion, ascites, and pericardial effusion, treatment response, and patient outcome. The Institutional Review Boards approved the collection of patients' clinical records. All data were anonymous, and informed consent was waived due to retrospective observational nature of this study. For patients whose disease was measurable by CT or magnetic resonance imaging (MRI), their responses were assessed according to revised-RECIST criteria. Complete response (CR), partial response (PR), progressive disease (PD), and stable disease (SD) were recorded accordingly[6].

\section{Statistical analysis}

The primary outcome was event-free survival (EFS) and overall survival (OS) rates. EFS was defined as the interval between diagnosis and disease progression, relapse, or death, and OS was defined as the interval between diagnosis and death from any cause or last contact. The Kaplan and Meier approach was used to estimate patient survival times. Kaplan Meier analysis was used to describe the time from IL2 exposure to follow-up, and the log-rank test was used to compare findings between effusion and control groups. $P<0.05$ was considered as significance difference. GraphPad Prism 8.0 was used for all statistical analyses and images.

\section{Results}

\section{Patients}


Between January $1^{\text {st }}, 2008$ and December $31^{\text {st }}, 2020,372$ patients were diagnosed with solid tumors, while 416 were diagnosed with lymphoma. Among them, forty patients with solid tumors and sixty-six patients with lymphoma were further diagnosed with pleural effusion, ascites, or pericardial effusion. A total of eighty-five patients received IL-2 injection while the remaining twenty-one patients did not. Indeed, twenty-one patients were diagnosed at early stage of this retrospective study. IL-2 injection was not routinely used to treat effusions at the time.

Among eighty-five patients in the effusion group, twenty-one had stage खll diseases (including T cell lymphoblastic lymphoma, B cell lymphoblastic lymphoma, primitive neuroectodermal tumor (PNET), HB, and pediatric pneumoblastoma (PPB) in twelve, three, two, and two cases, respectively), while the remaining sixty-four had stage IV diseases (including T cell lymphoblastic lymphoma, B cell lymphoblastic lymphoma, diffuse large B-cell lymphoma (DLBCL), Burkitt's lymphoma (BL), anaplastic large cell lymphoma (ALCL), rhabdomyosarcoma (RMS), NB, Ewing's, HB, PNET, and PPB in twenty-four, six, six, three, two, seven, four, four, four, three, and one case, respectively). Meanwhile, fifty-eight patients only had pleural effusion (including bilateral pleural effusions in twenty-nine patients), while fifteen only had ascites. The remaining twelve cases had concurrent pleural effusion, ascites, and pericardial effusion. Moreover, the remaining twelve patients all had bilateral pleural effusions.

Accordingly, for patients without IL-2 injection, 1 had stage II disease (HB in one), and one had stage IVs disease (NB in one). Nine cases had stage III diseases (including T cell lymphoblastic lymphoma in three cases, B cell lymphoblastic lymphoma in one, Ewing's in two, PNET in one, and HB in two), while the remaining ten patients had stage IV diseases (including T cell lymphoblastic lymphoma in two cases, B cell lymphoblastic lymphoma in one, DLBCL in two, ALCL in one, RMS in three, and PNET in one). Meanwhile, eleven patients only had pleural effusion (including bilateral pleural effusions in seven patients), while six only had ascites. The remaining four cases had concurrent pleural effusion, ascites, or pericardial effusion, all of which had bilateral pleural effusions. The detailed characteristics of one hundred and six patients are presented in Table 1.

\section{Table 1. The detailed characteristics of 106 patients}




\begin{tabular}{|c|c|c|c|c|}
\hline & \multicolumn{2}{|c|}{ Effusion group } & \multicolumn{2}{|c|}{ Control group } \\
\hline & Solid tumor & Lymphoma & Solid tumor & Lymphoma \\
\hline Age $($ mean \pm se $)$ & $5.42 \pm 3.97$ & $8.02 \pm 3.43$ & $4.96 \pm 3.7$ & $9.8 \pm 2.39$ \\
\hline \multicolumn{5}{|l|}{ Gender } \\
\hline Male & 15 & 32 & 6 & 6 \\
\hline Female & 14 & 24 & 5 & 4 \\
\hline \multicolumn{5}{|l|}{ stage } \\
\hline II & & & 1 & \\
\hline III & 4 & 15 & 5 & 4 \\
\hline IV & 24 & 44 & 4 & 6 \\
\hline IVs & & & 1 & \\
\hline \multicolumn{5}{|l|}{ Histology } \\
\hline RMS & 7 & & 3 & \\
\hline NB & 4 & & 1 & \\
\hline $\mathrm{PPB}$ & 3 & & & \\
\hline Ewing's sarcoma & 4 & & 2 & \\
\hline $\mathrm{HB}$ & 6 & & 3 & \\
\hline PNET & 5 & & 2 & \\
\hline $\mathrm{T}$ cell lymphoblas & tic lymphoma & 36 & & 5 \\
\hline B cell lymphoblas & tic lymphoma & 9 & & 2 \\
\hline DLBCL & & 6 & & 2 \\
\hline BL & & 3 & & \\
\hline ALCL & & 2 & & 1 \\
\hline
\end{tabular}

Note: RMS, rhabdomyosarcoma; NB, neuroblastoma; PPB, pediatric pneumoblastoma; HB, hepatoblastoma; PNET, primitive neuroectodermal tumor; DLBCL, diffuse large B-cell lymphoma; BL, Burkitt's lymphoma; ALCL, anaplastic large cell lymphoma

Dyspnea, cough, and discomfort were the most frequently reported symptoms of pleural and pericardial effusions, whereas abdominal distension, abdominal pain, and edema were the most widely recognized symptoms of ascites.

\section{Treatment}

While all patients in the effusion group were diagnosed with a malignant tumor and pleural effusion, ascites, or pericardial effusion, IL-2 injection therapy may be administered without a pathological diagnosis as long as malignant lesions associated with pleural, abdominal, or pericardial effusion were 
identified on imaging. We obtained written informed consent from patients' parents or legal guardians before starting the therapy. First, patients performed thoracic, abdominal cavity, or pericardial cavity puncture with the indwelling of a drainage tube, and pathology was simultaneously obtained if permitted.

In patients with unilateral pleural effusion, no more than $600 \mathrm{~mL}$ fluid was drained on the first day and no more than $1000 \mathrm{~mL}$ each day; for patients with bilateral pleural effusions, the total drainage volume was the same. Ascites should not exceed $1000 \mathrm{~mL}$ each time, and pericardial effusion should not exceed 100 $\mathrm{mL}$ each time. In the presence of multi-cavity effusions, the drained effusion amount should be reduced as appropriate, and static electricity of hydration solution should be applied simultaneously.

After discharge, $0.9 \%$ sodium chloride injection $(0.9 \% \mathrm{NaCl}$, maximum $100 \mathrm{~mL})$ combined with IL-2 (5.0$10.0 \times 106 \mathrm{IJ} / \mathrm{m} 2$, maximum dose $10.0 \times 106 \mathrm{IU})$ and DEX $(5 \mathrm{mg})$ was injected via the drainage tube. The injection was administered every other day, and the total number of injections was not strictly limited, which was stopped when ultrasound confirmed that the effusion was no more than $2 \mathrm{~cm}$ or disappeared. For patients with bilateral pleural effusions or multi-cavity effusions, the maximum total doses of IL-2 and DEX were maintained at $10.0 \times 106 \mathrm{IU}$ and $5 \mathrm{mg}$, respectively, which should be divided according to $0.9 \% \mathrm{NaCl}$ volume. It should be noted that $0.9 \% \mathrm{NaCl}$ volume should not exceed $50 \mathrm{~mL}$ during unilateral thoracic injection and should not exceed $20 \mathrm{~mL}$ during pericardial cavity injection. Besides, the injection time should be more than 1 hour. It was advisable to use an injection pump to pump the fluid at a uniform rate. No strict requirement was found for the intraperitoneal injection rate or the fluid amount. After injection, the drainage tube was closed until the following day, and the child was instructed to change the position as much as possible to ensure the wider distribution of IL-2.

Chemotherapy might be initiated during IL-2 therapy. All patients in the control group were treated according to pathology diagnosis without IL-2 therapy.

\section{Response}

A total of four hundred and eighty one injections were administered for eight-five patients. The average number of injections into the pericardial cavity was two, while that into pleural and intraperitoneal cavities were three to four. Only one patient with $T$ cell lymphoblastic lymphoma received the maximum seven pleural injections.

Among the eighty-five patients, half had bloody drainage fluid, and tumor exfoliated cells were detected in the drainage fluid from thirty-one patients. The injections generally had limited toxicity, and only eleven patients developed a moderate fever on the first day of injection. No patient developed respiratory distress related to IL-2 injection therapy. Simultaneously, no allergic reaction or catheter-related infection occurred.

\section{Outcome}

In this study, patients with solid tumors were mainly treated according to the protocols from COG or International Society of Pediatric Oncology group (SIOP)[7-13], whereas those with lymphoma were 
mainly treated in line with BFM protocols[14-17]. All patients in the effusion group achieved CR of effusions from IL-2 injection therapy, even though one patient received seven injections altogether. No recurrence of pleural effusion, ascites, or pericardial effusion was noticed.

Among patients in the effusion group with lymphoma, four died of disease progression, and two had relapsed disease (including three with T cell lymphoblastic lymphoma, one with DLBCL, one with BL, and one with $A L C L$ ). One of the two patients with relapsed disease died, while the other with ALCL achieved SD after crizotinib treatment[18]. The five-year EFS and five-year OS for patients with lymphoma were $89.3 \% \pm 31.2 \%(95 \% \mathrm{Cl}, 80.9 \%$ to $97.6 \%)$ and $91.1 \% \pm 28.8 \%(95 \% \mathrm{Cl}, 83.4 \%$ to $98.8 \%)$, respectively. Among patients in the control group with lymphoma, two died of disease progression, and two had relapsed disease (including one with T cell lymphoblastic lymphoma, two with DLBCL, and one with ALCL). Both patients with relapsed disease died. The five-year EFS and five-year OS for patients with lymphoma were $60 \% \pm 51.6 \%(95 \% \mathrm{Cl}, 23.1 \%$ to $96.9 \%)$. The Kaplan Meier analysis demonstrated significant differences between the two groups with both of which $p<0.01$. When we calculated the hazard ratio (HR), we found that it was 0.191 for EFS and 0.161 for OS (Figure 1).

For patients in the effusion group with solid tumors, four died due to disease progression, and eight got relapsed diseases (including three with RMS, one with NB, three with PPB, one with Ewing's sarcoma, one with $\mathrm{HB}$, and one with PNET). Seven of the eight patients with relapsed disease died, while the other with HB achieved secondary CR after irinotecan treatment[19]. The five-year EFS and five-year OS were $62.1 \%$ $\pm 49.4 \%(95 \% \mathrm{Cl}, 43.3 \%$ to $80.9 \%)$ and $65.5 \% \pm 48.4 \%$ (95\% $\mathrm{Cl}, 47.1 \%$ to $83.9 \%)$, respectively. For patients in the control group, among patients with solid tumors, two died due to disease progression, and four got relapsed diseases (including three with RMS, one with NB, one with Ewing's sarcoma, and one with PNET). Three patients with relapsed disease died, while the other with NB achieved PR after irinotecan treatment and alive with tumor. The five-year EFS and five-year OS were $45.5 \% \pm 52.2 \%(95 \% \mathrm{Cl}, 10.4 \%$ to $80.5 \%)$ and $54.5 \% \pm 52.2 \%(95 \% \mathrm{Cl}, 19.5 \%$ to $89.6 \%)$, respectively. The Kaplan Meier analysis showed no statistical difference between the two groups with both of which $p>0.05$ (Figure 2).

However, when lymphoma and solid tumor patients were combined, the Kaplan Meier analysis revealed a significant difference between the two groups, with $p<0.01$ for EFS and OS. HR $=0.344$ between OS and 0.352 between EFS (Figure 3).

The mean effusion control time ( $<2 \mathrm{~m}$ pleural effusion, or disappearance of ascites or pericardial injection) for the effusion group was $5.76 \pm 1.95$ days ( $95 \% \mathrm{Cl}, 5.34$ to 6.19 days), while for the control group was $18.3 \pm 5.25$ days $(95 \% \mathrm{Cl}, 15.94$ to 20.72 days), which had statistical difference $(p<0.01)$.

\section{Discussion}

Several reports exist on the small size of pediatric patients with pleural effusion or ascites[2, 20, 21]. However, no existing study has been conducted to investigate the role of IL-2 in pediatric cancer patients with malignant pleural effusion, ascetics, and pericardial effusion. It has been well recognized that IL-2 plays a vital role in activating and maintaining specific and nonspecific immune responses[22]. IL-2 can 
induce activated natural killer cells and enhance antibody-dependent cellular cytotoxicity[23]. As such, IL2 injection is applied in treating adult tumors[24, 25].

Remarkably, we found that DEX administration combined with IL-2 via thoracic, intraperitoneal, or pericardial injection quickly resolved the fluid and immediately relieved the discomfort of patients. Moreover, no recurrence of pleural effusion, ascites, or pericardial effusion was observed in our patients. These results suggested that IL-2 played a particular role in treating pleural effusion, ascites, and pericardial effusion. Initially, we administered IL-2 without obtaining a pathological diagnosis to save the patient's life when imaging examination revealed a potentially malignant tumor associated with pleural effusion, ascites, or pericardial effusion, especially in critically ill children. Our treatment is effective, as all symptoms, including chest pain and dyspnea, improved to varying degrees in affected children. The mean effusion control time for the effusion group was $5.76 \pm 1.95$ days vs. $18.3 \pm 5.25$ days for the control group, which significantly differed. Although tumor-exfoliated cells were only detected in thirty-one patients, there was no misdiagnosis, and this procedure has become our regular treatment model.

Pleural effusion, ascites, and pericardial effusion are the possible signs of tumor spread, indicating the contamination of pleural space or abdominal cavity; thus, they are often considered negative prognostic factors $[3,21]$. However, as reported in the study on NB patients from St. Jude Children's Research Hospital, no difference is found in the survival related to a pleural effusion[2].

Our retrospective study included many tumors, so it was difficult to determine the tumor prognosis from survival. However, the five-year EFS and five-year OS for patients in the effusion group with lymphoma were $89.3 \% \pm 31.2 \%(95 \% \mathrm{Cl}, 80.9 \%$ to $97.6 \%)$ and $91.1 \% \pm 28.8 \%(95 \% \mathrm{Cl}, 83.4 \%$ to $98.8 \%)$ while those for patients in the control group with lymphoma were $60 \% \pm 51.6 \%(95 \% \mathrm{Cl}, 23.1 \%$ to $96.9 \%)$. There was a statistical difference, and HR was $<1$, indicating that IL-2 therapy is a protective factor for survival. The NHL-BFM90 study reports a 90\% EFS rate for patients with T-cell lymphoblastic lymphoma and a $93.9 \%$ three-year EFS for those with mature B cell lymphoma. In our study, the five-year EFS in the effusion group was $89.3 \% \pm 31.2 \%$, comparable to those reported in other studies but not in the control group. As such, our study showed that with the appropriate treatment, pleural effusion, ascites, and pericardial effusion were not poor prognostic factors.

The five-year EFS and five-year OS for patients in the effusion group with solid tumors were $62.1 \% \pm 49.4 \%$ $(95 \% \mathrm{Cl}, 43.3 \%$ to $80.9 \%)$ and $65.5 \% \pm 48.4 \%(95 \% \mathrm{Cl}, 47.1 \%$ to $83.9 \%)$, vs. in the control group, where the five-year EFS and five-year OS were $45.5 \% \pm 52.2 \%(95 \% \mathrm{Cl}, 10.4 \%$ to $80.5 \%)$ and $54.5 \% \pm 52.2 \%(95 \% \mathrm{Cl}$, $19.5 \%$ to $89.6 \%$ ). Nowadays, the 5 -year OS for patients with pediatric solid tumors ranges from $50 \%$ to $80 \%[9,26,27]$. Our five-year OS was slightly lower than the average level, which might be because the three children diagnosed with type III PPB died. Furthermore, despite the lack of a statistically significant difference between the two groups ( $p=0.593)$, it is obvious that interleukin-2 therapy has a beneficial effect; at least, it does not reduce survival. Moreover, when all patients were combined, a statistically significant difference between the two groups was observed. The reason might be that the number of patients in the solid tumor group was relatively small. 
It is known that IL-2 administration is associated with numerous side effects, and there is evidence that increased doses of IL-2 lead to increased toxicity[28]. Several dosage regimens, including high intravenous doses $(720,000$ or 600,000 international units $/ \mathrm{kg})$, have been applied for obtaining the maximum therapeutic benefit[24]. At our hospital, the recommended dosage of IL-2 is 1 million IU/ m2/ time (maximum dose $10.0 \times 106 \mathrm{IU}$ ). Our study suggested that IL-2 injection following this dose was well tolerated and highly safe. The possible mechanism of IL-2 in treating adult pleural effusion is that IL-2 increases the numbers of CD3+T cells and NK cells in the pleural space and enhances the immune response, thus reducing the incidence of pleural effusion. However, the mechanism of IL-2 in treating pediatric cancers remains unknown. Most pediatric cancers arise from embryonal cells that are distinctly different from epithelial cells, and the immune response itself is also markedly different between adults and children. Consequently, the low mutational burden and relative lack of neoantigen expression are among the defining traits of pediatric cancers, which have limited their immune targeting susceptibility[29].

To sum up, this retrospective research demonstrates that thoracic, intraperitoneal injection or pericardial injection of DEX plus IL-2 is an effective and highly safe treatment for pediatric cancers with pleural effusion, ascites, and pericardial effusion. However, further randomized trials are warranted to provide more real evidence to evaluate the efficacy of IL-2 in treating pediatric patients.

\section{List Of Abbreviations}

$\begin{array}{ll}\text { IL-2 } & \text { interleukin-2 } \\ \text { DEX } & \text { dexamethasone } \\ \text { EFS } & \text { event free survival } \\ \text { OS } & \text { overall survival } \\ \text { NB } & \text { neuroblastoma } \\ \text { HB } & \text { hepatoblastoma } \\ \text { COG } & \text { Children's Oncology Group } \\ \text { SE } & \text { small effusion } \\ \text { ME } & \text { moderate effusion } \\ \text { CT } & \text { computer tomography } \\ \text { LE } & \text { large effusion } \\ \text { G1 } & \text { grade 1 }\end{array}$




$\begin{array}{ll}\text { G2 } & \text { grade 2 } \\ \text { G3 } & \text { grade 3 } \\ \text { S } & \text { small } \\ \text { M } & \text { moderate } \\ \text { L } & \text { large }\end{array}$

MRI magnetic resonance imaging

$\mathrm{CR} \quad$ complete response

PR partial response

PD progressive disease

SD stable disease

PNET primitive neuroectodermal tumor

PPB pediatric pneumoblastoma

DLBCL diffuse large B-cell lymphoma

$\mathrm{BL} \quad$ Burkitt's lymphoma

ALCL anaplastic large cell lymphoma

RMS rhabdomyosarcoma

$\mathrm{NaCl}$ sodium chloride injection

SIOP Society of Pediatric Oncology group

\section{Declarations}

Ethics approval and consent to participate[Approved by the Ethical Institution of the first hospital of Jilin university. Because of its retrospective manner, informed consent was waived by the Ethical Institution of the first hospital of Jilin university

Statement: All methods were carried out in accordance with relevant guidelines and regulations.

Consent to ParticipateIThis is a retrospective study, informed consent was waived by the Ethical Institution of the first hospital of Jilin university. However, when we performed the IL-2 injection, we obtained written informed consent from patients' parents or legal guardians before starting the therapy. 
informed consent was obtained by each patients or their parents.

Consent for publication: Not applicable

Availability of data and materials $\square$ Patient's data were available in medical records room of the first hospital of Jilin university. The datasets generated and/or analysed during the current study are not publicly available due to they are files in medical records room in our hospital, but are available from the corresponding author on reasonable request.

Competing interests $₫$ The authors indicated no potential conflicts of interest.

Funding Project supported by the Natural Science Foundation of Jilin Province, China. (Grant No. 182440JC010347774)

\section{Authors' contributions[}

1)YTZ: Dr. Z made substantial contributions to design of the work; drafted the manuscript; agree to be accountable for all aspects of the work in ensuring that questions related to the accuracy or integrity of any part of the work are appropriately investigated and resolved. All authors have read and approved the manuscript.

2)XDZ: Dr. Z made substantial contributions to design of the work; drafted the manuscript; all authors have read and approved the manuscript; and agree to be accountable for all aspects of the work in ensuring that questions related to the accuracy or integrity of any part of the work are appropriately investigated and resolved.

3)YLG: Dr. G made substantial contributions to the design of the work revised the manuscript critically; all authors have read and approved the manuscript.; and agree to be accountable for all aspects of the work in ensuring that questions related to the accuracy or integrity of any part of the work are appropriately investigated and resolved.

4)JC: Dr. C made substantial contributions to design of the work; drafted the manuscript; agree to be accountable for all aspects of the work in ensuring that questions related to the accuracy or integrity of any part of the work are appropriately investigated and resolved. All authors have read and approved the manuscript.

Acknowledgements $\square$ Project supported by the Natural Science Foundation of Jilin Province, China. (Grant No. 182440JC010347774)

Authors' information (optional)nNot applicable

\section{References}


1. Towu E, Kiely E, Pierro A, Spitz L: Outcome and complications after resection of hepatoblastoma. J Pediatr Surg 2004, 39(2):199-202; discussion 199-202.

2. Gupta H, Conrad J, Khoury JD, McGregor LM, Krasin MJ, Dome JS, Santana VM, Davidoff AM: Significance of pleural effusion in neuroblastoma. Pediatric blood \& cancer 2007, 49(7):906-908.

3. McCarten KM, Metzger ML, Drachtman RA, Pei Q, Friedman DL, Schwartz CL, Kelly KM: Significance of pleural effusion at diagnosis in pediatric Hodgkin lymphoma: a report from Children's Oncology Group protocol AHOD0031. Pediatr Radio/ 2018, 48(12):1736-1744.

4. EASL clinical practice guidelines on the management of ascites, spontaneous bacterial peritonitis, and hepatorenal syndrome in cirrhosis. Journal of hepatology 2010, 53(3):397-417.

5. Weitzman LB, Tinker WP, Kronzon I, Cohen ML, Glassman E, Spencer FC: The incidence and natural history of pericardial effusion after cardiac surgery-an echocardiographic study. Circulation 1984, 69(3):506-511.

6. Watanabe H, Okada M, Kaji Y, Satouchi M, Sato Y, Yamabe Y, Onaya H, Endo M, Sone M, Arai Y: [New response evaluation criteria in solid tumours-revised RECIST guideline (version 1.1)]. Gan to kagaku ryoho Cancer \& chemotherapy 2009, 36(13):2495-2501.

7. Arndt CA, Stoner JA, Hawkins DS, Rodeberg DA, Hayes-Jordan AA, Paidas CN, Parham DM, Teot LA, Wharam MD, Breneman JC et al: Vincristine, actinomycin, and cyclophosphamide compared with vincristine, actinomycin, and cyclophosphamide alternating with vincristine, topotecan, and cyclophosphamide for intermediate-risk rhabdomyosarcoma: children's oncology group study D9803. Journal of clinical oncology : official journal of the American Society of Clinical Oncology 2009, 27(31):5182-5188.

8. Borinstein SC, Steppan D, Hayashi M, Loeb DM, Isakoff MS, Binitie O, Brohl AS, Bridge JA, Stavas M, Shinohara ET et al: Consensus and controversies regarding the treatment of rhabdomyosarcoma. Pediatric blood \& cancer 2018, 65(2).

9. Grier HE, Krailo MD, Tarbell NJ, Link MP, Fryer CJ, Pritchard DJ, Gebhardt MC, Dickman PS, Perlman EJ, Meyers PA et al: Addition of ifosfamide and etoposide to standard chemotherapy for Ewing's sarcoma and primitive neuroectodermal tumor of bone. The New England journal of medicine 2003, 348(8):694-701.

10. Zhang YT, Chang J, Xu HM, Li YN, Zhong XD, Liu ZL: Treatment of Neuroblastoma with a Novel Delayed Intensification Chemotherapy. Indian journal of pediatrics 2019, 86(2):126-131.

11. Malogolowkin MH, Katzenstein HM, Krailo M, Chen Z, Quinn JJ, Reynolds M, Ortega JA: Redefining the role of doxorubicin for the treatment of children with hepatoblastoma. Journal of clinical oncology : official journal of the American Society of Clinical Oncology 2008, 26(14):2379-2383.

12. Zsiros J, Brugieres L, Brock P, Roebuck D, Maibach R, Zimmermann A, Childs M, Pariente D, Laithier V, Otte JB et al: Dosedense cisplatin-based chemotherapy and surgery for children with high-risk hepatoblastoma (SIOPEL-4): a prospective, single-arm, feasibility study. The Lancet Oncology 2013, 14(9):834-842. 
13. Bisogno G, Brennan B, Orbach D, Stachowicz-Stencel T, Cecchetto G, Indolfi P, Bien E, Ferrari A, Dommange-Romero F: Treatment and prognostic factors in pleuropulmonary blastoma: an EXPeRT report. European journal of cancer (Oxford, England : 1990) 2014, 50(1):178-184.

14. Eckert C, von Stackelberg A, Seeger K, Groeneveld TW, Peters C, Klingebiel T, Borkhardt A, Schrappe $M$, Escherich $G$, Henze $G$ : Minimal residual disease after induction is the strongest predictor of prognosis in intermediate risk relapsed acute lymphoblastic leukaemia - long-term results of trial ALL-REZ BFM P95/96. European journal of cancer (Oxford, England : 1990) 2013, 49(6):1346-1355.

15. Laver JH, Mahmoud H, Pick TE, Hutchinson RE, Weinstein HJ, Schwenn M, Weitzman S, Murphy SB, Ochoa S, Shuster JJ: Results of a randomized phase III trial in children and adolescents with advanced stage diffuse large cell non Hodgkin's lymphoma: a Pediatric Oncology Group study. Leukemia \& lymphoma 2001, 42(3):399-405.

16. Meinhardt A, Burkhardt B, Zimmermann M, Borkhardt A, Kontny U, Klingebiel T, Berthold F, JankaSchaub G, Klein C, Kabickova E et al: Phase II window study on rituximab in newly diagnosed pediatric mature B-cell non-Hodgkin's lymphoma and Burkitt leukemia. Journal of clinical oncology : official journal of the American Society of Clinical Oncology 2010, 28(19):3115-3121.

17. Laver JH, Kraveka JM, Hutchison RE, Chang M, Kepner J, Schwenn M, Tarbell N, Desai S, Weitzman $\mathrm{S}$, Weinstein HJ et al: Advanced-stage large-cell lymphoma in children and adolescents: results of a randomized trial incorporating intermediate-dose methotrexate and high-dose cytarabine in the maintenance phase of the APO regimen: a Pediatric Oncology Group phase III trial. Journal of clinical oncology : official journal of the American Society of Clinical Oncology 2005, 23(3):541-547.

18. Mossé YP, Voss SD, Lim MS, Rolland D, Minard CG, Fox E, Adamson P, Wilner K, Blaney SM, Weigel BJ: Targeting ALK With Crizotinib in Pediatric Anaplastic Large Cell Lymphoma and Inflammatory Myofibroblastic Tumor: A Children's Oncology Group Study. Journal of clinical oncology : official journal of the American Society of Clinical Oncology 2017, 35(28):3215-3221.

19. Zhang YT, Feng LH, Zhong XD, Wang LZ, Chang J: Vincristine and irinotecan in children with relapsed hepatoblastoma: a single-institution experience. Pediatric hematology and oncology 2015, 32(1):1825.

20. Sirvent N, Kanold J, Levy C, Dubousset J, Zucker JM, Philip T, Demaille MC, Robert A, Vannier JP, Oberlin O: Non-metastatic Ewing's sarcoma of the ribs: the French Society of Pediatric Oncology Experience. European journal of cancer (Oxford, England : 1990) 2002, 38(4):561-567.

21. Di Carlo D, Ferrari A, Toffolutti T, Milano GM, Manzitti C, Ruggiero A, Dall'Igna P, Melchionda F, Zanetti I, Scarzello G et al: Prognostic role of pleural effusion or ascites in localized rhabdomyosarcoma. Pediatric blood \& cancer 2019, 66(11):e27932.

22. Voss SD, Hong R, Sondel PM: Severe combined immunodeficiency, interleukin-2 (IL-2), and the IL-2 receptor: experiments of nature continue to point the way. Blood 1994, 83(3):626-635.

23. Ladenstein R, Pötschger U, Valteau-Couanet D, Luksch R, Castel V, Yaniv I, Laureys G, Brock P, Michon JM, Owens C et al: Interleukin 2 with anti-GD2 antibody ch14.18/CHO (dinutuximab beta) in patients 
with high-risk neuroblastoma (HR-NBL1/SIOPEN): a multicentre, randomised, phase 3 trial. The Lancet Oncology 2018, 19(12):1617-1629.

24. Han L, Jiang Q, Yao W, Fu T, Zeng Q: Thoracic injection of low-dose interleukin-2 as an adjuvant therapy improves the control of the malignant pleural effusions: a systematic review and metaanalysis base on Chinese patients. BMC cancer 2018, 18(1):725.

25. Blanchard DK, Kavanagh JJ, Sinkovics JG, Cavanagh D, Hewitt SM, Djeu JY: Infiltration of interleukin-2-inducible killer cells in ascitic fluid and pleural effusions of advanced cancer patients. Cancer research 1988, 48(22):6321-6327.

26. Park JR, Kreissman SG, London WB, Naranjo A, Cohn SL, Hogarty MD, Tenney SC, Haas-Kogan D, Shaw PJ, Kraveka JM et al: Effect of Tandem Autologous Stem Cell Transplant vs Single Transplant on Event-Free Survival in Patients With High-Risk Neuroblastoma: A Randomized Clinical Trial. Jama 2019, 322(8):746-755.

27. Meyers RL, Maibach R, Hiyama E, Häberle B, Krailo M, Rangaswami A, Aronson DC, Malogolowkin $\mathrm{MH}$, Perilongo G, von Schweinitz $\mathrm{D}$ et al: Risk-stratified staging in paediatric hepatoblastoma: a unified analysis from the Children's Hepatic tumors International Collaboration. The Lancet Oncology 2017, 18(1):122-131.

28. Schwartzentruber DJ: Guidelines for the safe administration of high-dose interleukin-2. Journal of immunotherapy (Hagerstown, Md : 1997) 2001, 24(4):287-293.

29. Campbell BB, Light N, Fabrizio D, Zatzman M, Fuligni F, de Borja R, Davidson S, Edwards M, Elvin JA, Hodel KP et al: Comprehensive Analysis of Hypermutation in Human Cancer. Cell 2017, 171(5):10421056.e1010.

\section{Figures}
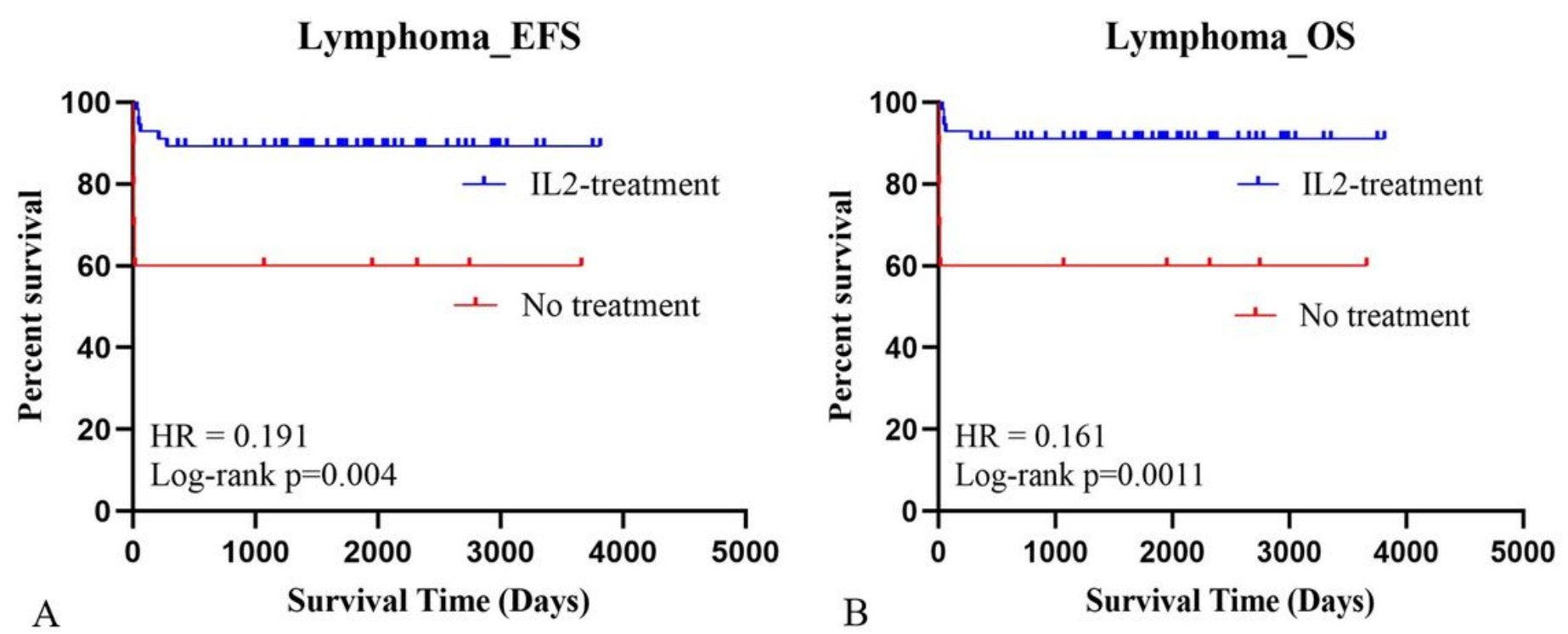
Figure 1

A: The Kaplan Meier analysis demonstrated significant differences between the effusion group and control group for lymphoma patients in EFS $(p<0.01)$. The hazard ratio was 0.191 for EFS. A: The Kaplan Meier analysis demonstrated significant differences between the effusion group and control group for lymphoma patients in OS $(p<0.01)$. The hazard ratio was 0.161 for OS.

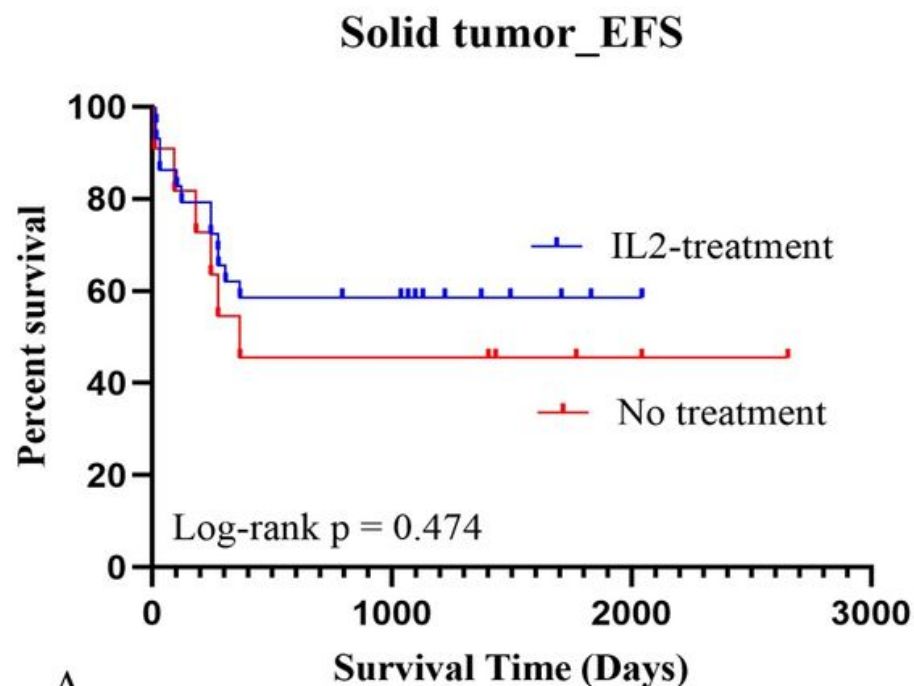

A

Survival Time (Days)

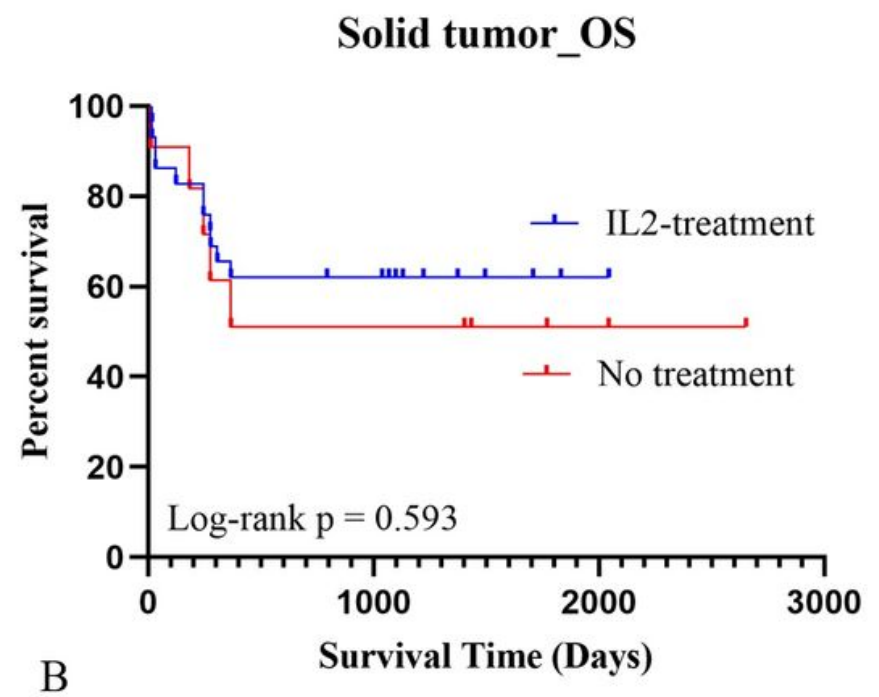

Figure 2

A: The Kaplan Meier analysis demonstrated no differences between the effusion group and control group for solid tumor patients in EFS ( $p>0.05)$. A: The Kaplan Meier analysis demonstrated no differences between the effusion group and control group for solid tumor patients in OS ( $p>0.05)$.

Effusion_IL2_EFS

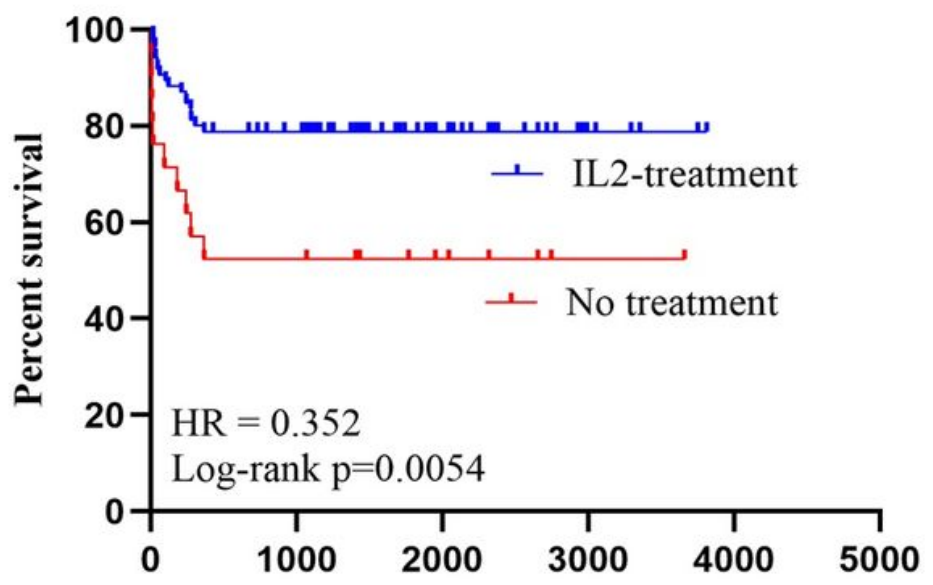

A

Survival Time (Days)
Effusion_IL2_OS

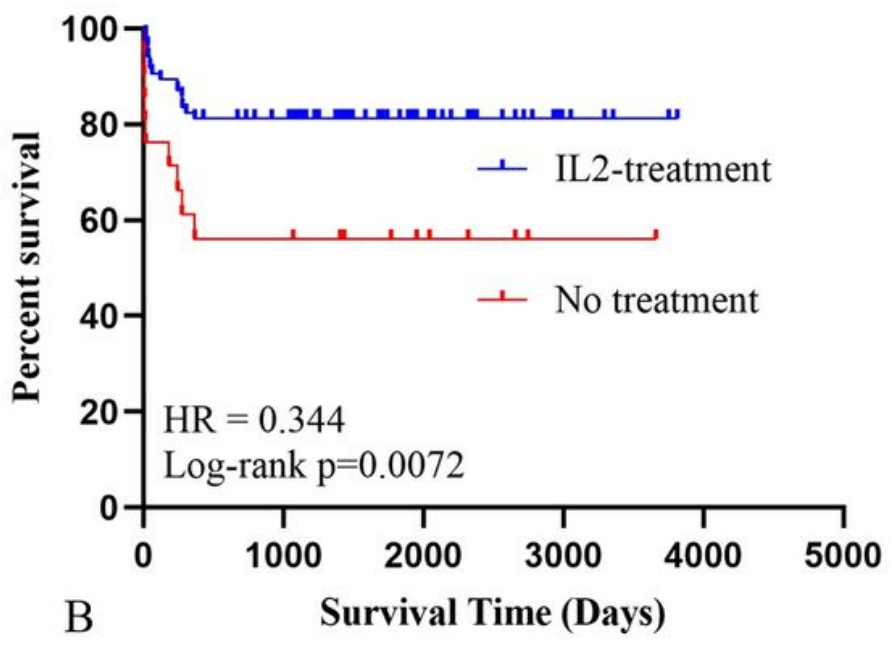




\section{Figure 3}

A: The Kaplan Meier analysis demonstrated significant differences between the effusion group and control group for pediatric cancer patients in EFS $(p<0.01)$. The hazard ratio was 0.352 for EFS. A: The Kaplan Meier analysis demonstrated significant differences between the effusion group and control group for pediatric cancer patients in OS $(p<0.01)$. The hazard ratio was 0.344 for OS. 